\title{
KAPOSI'S DISEASE MANIFESTING IN THE EYE*
}

\author{
BY \\ IAN SACKS \\ Bulawayo, Southern Rhodesia
}

An African girl aged 12 was referred with ? haemangioma of the conjunctiva.

Examination.-A cherry-red pedunculated mass arose from the lower fornix of the conjunctiva of the right eye; it was only visible on everting the lower eyelid (Fig. 1a, 1b).

No skin lesions were found on the extremities or abdominal wall, but numerous submandibular, axillary, and inguinal glands were palpable.

The Wassermann reaction was negative.

The blood count was normal with relative lymphocytosis.

A radiograph of the chest showed slight enlargement of the hilar glands.

Operation.-The conjunctival tumour was easily removed; one inguinal gland removed for biopsy was found to be haemorrhagic.

Pathologist's Report:

Conjunctival Tumour: "structure like a haemangiosarcoma which does not appear of great malignancy-indistinguishable from that found in Kaposi's disease".

Lymph Gland from Inguinal Region: "replaced by a similar type of growth".

Diagnosis.-Kaposi's tumour of the conjunctiva.

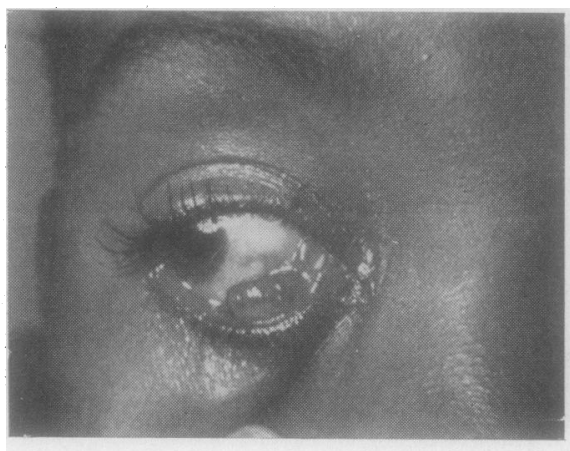

(a)

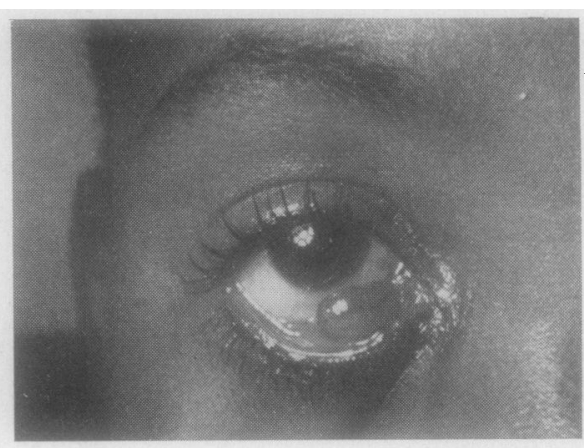

(b)

Fig. 1.-Right eye with lower lid everted and tumour protruding: (a) looking right ; $(b)$ looking straight ahead

\section{Comment}

A Kaposi's tumour is a rare manifestation in the eye, and Duke-Elder (1938) reports only two others arising from the conjunctiva (Greeff, 1901; Heine, 1906).

\section{REFERENCES}

DUKE-Elder, S. (1938). “Text-book of Ophthalmology”, vol. 2, pp. 1741, 1742. Kimpton, London.

GreEFF, R. (1901). Arch. Augenheilk., 42, 99.

HeIne, L. (1906). Klin. Mbl. Augenheilk., 44 (2), 460.

* Received for publication April 30, 1956. 